\title{
Multifunctional Heterogeneous Catalysts for the Selective Conversion of Glycerol into Methyl Lactate
}

\author{
Zhenchen Tang, $^{\dagger}$ Sonia L. Fiorilli, ${ }^{\ddagger}$ Hero J. Heeres, ${ }^{\dagger}{ }^{\circ}$ and Paolo P. Pescarmona ${ }^{*}{ }^{\dagger}$ \\ ${ }^{\dagger}$ Chemical Engineering Group, Engineering and Technology institute Groningen (ENTEG), University of Groningen, Nijenborgh 4, \\ 9747 AG Groningen, The Netherlands \\ ${ }^{\ddagger}$ Department of Applied Science and Technology, Politecnico di Torino, Corso Duca degli Abruzzi 24, 10129 Torino, Italy
}

Supporting Information

ABSTRACT: Multifunctional catalytic systems consisting of physical mixtures of Au nanoparticles (2-3 nm) supported on metal oxides and Sn-MCM-41 nanoparticles (50-120 nm) were synthesized and investigated for the selective conversion of glycerol to methyl lactate. The Au catalyst promotes the oxidation of glycerol to trioses, whereas the solid acid SnMCM-41 catalyzes the rearrangement of the intermediate trioses to methyl lactate. Among the supported Au nanoparticles, $\mathrm{Au} / \mathrm{CuO}$ led to the highest yield and selectivity toward methyl lactate, while the Sn-MCM-41 nanoparticles showed much better catalytic performance than a benchmark solid acid catalyst (USY zeolite). The activity of the multifunctional catalytic system was further optimized by

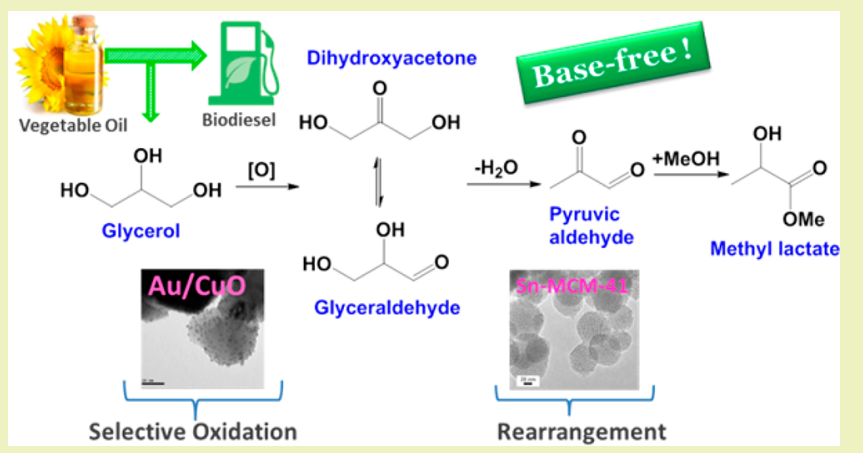
tuning the calcination temperature, the gold loading in the $\mathrm{Au} / \mathrm{CuO}$ catalyst, and the $\mathrm{Au} / \mathrm{Sn}$ molar ratio, reaching $63 \%$ yield of methyl lactate $(\mathrm{ML})$ at $95 \%$ glycerol conversion. This catalytic system also showed excellent reusability. The catalytic results were rationalized on the basis of a detailed characterization by means of TEM, $\mathrm{N}_{2}$-physisorption, UV-vis spectroscopy, and by FT-IR using probe molecules ( $\mathrm{CO}$ and ethanol).

KEYWORDS: Glycerol, Methyl lactate, Gold catalysis, Sn-MCM-41, Multifunctional catalysts

\section{INTRODUCTION}

The catalytic conversion of renewable, biobased compounds into value-added chemicals is receiving growing interest as a consequence of the increasing awareness of sustainability issues related to the use of fossil fuels (depletion and global warming). ${ }^{1,2}$ Glycerol, the main byproduct (10 wt \%) of the biodiesel manufacturing process, is considered as one of the primary biobased platform molecules. ${ }^{3,4}$ The steep increase in the global biodiesel production levels in the past decade has resulted in a surplus of glycerol. ${ }^{5}$ Therefore, converting glycerol into high-value chemicals has gained extensive attention from academia and industry. ${ }^{6-8}$ The high content of hydroxyl groups in glycerol offers various options for its conversion into high-value products, such as dehydration to acrolein, hydrogenolysis to propanediol and selective oxidation to carboxylic acids or their esters. ${ }^{3,7}$ Among the products of glycerol oxidation, alkyl lactates and lactic acid are considered as attractive platform molecules since the two functional groups $\left(-\mathrm{OH}\right.$ and $\left.-\mathrm{CO}_{2} \mathrm{R}\right)$ enable a large number of transformations into products with wide range of applications. Alkyl lactates can be used as green solvents, whereas lactic acid is a potential source for the production of biodegradable poly(lactic acid), acrylic acid, pyruvic acid, propanediol and propionic acid. ${ }^{3,9}$ Currently, up to $90 \%$ of commercial lactic acid is produced by fermentation of carbohydrates. This production route suffers from environmental issues related to large amounts of calcium sulfate sludge formed in the separation and purification steps. ${ }^{10,11}$ The development of efficient chemocatalytic routes to produce lactic acid/lactate from biomass represents an attractive and sustainable alternative. Many studies have been dedicated to the direct conversion of glycerol to lactic acid/lactate in a one-pot reaction (Scheme 1). ${ }^{12-17}$ The first investigation was conducted in harsh alkaline hydrothermal conditions (4.75 equiv of $\mathrm{NaOH} / \mathrm{KOH}$ to glycerol at $300{ }^{\circ} \mathrm{C}$ ) and yielded $90 \%$ of sodium or potassium lactate as product. ${ }^{17}$ Milder temperature could be used when both noble metal catalysts $\left(\mathrm{Au} / \mathrm{TiO}_{2}\right.$ and $\mathrm{AuPt} / \mathrm{TiO}_{2}, 86 \%$ selectivity at $\sim 30 \%$ conversion at $90{ }^{\circ} \mathrm{C}$ ) and a homogeneous base (4 equiv of $\mathrm{NaOH}$ to glycerol) were employed. ${ }^{13}$ The homogeneous base has been proposed to have two crucial functions: (1) to promote the initial deprotonation of one of the hydroxyl groups of glycerol; (2) to accelerate the conversion of the triose intermediates, dihydroxyacetone (DHA) and glyceraldehyde (GLAD) (Scheme 1), to lactic acid (lactate). ${ }^{13}$ However, the presence of a homogeneous base in the reaction system leads to a lactate

Received: May 18, 2018

Revised: June 19, 2018

Published: June 25, 2018 
Scheme 1. Catalytic Route from Glycerol to Methyl Lactate (ML) and Possible Side Products (in gray)

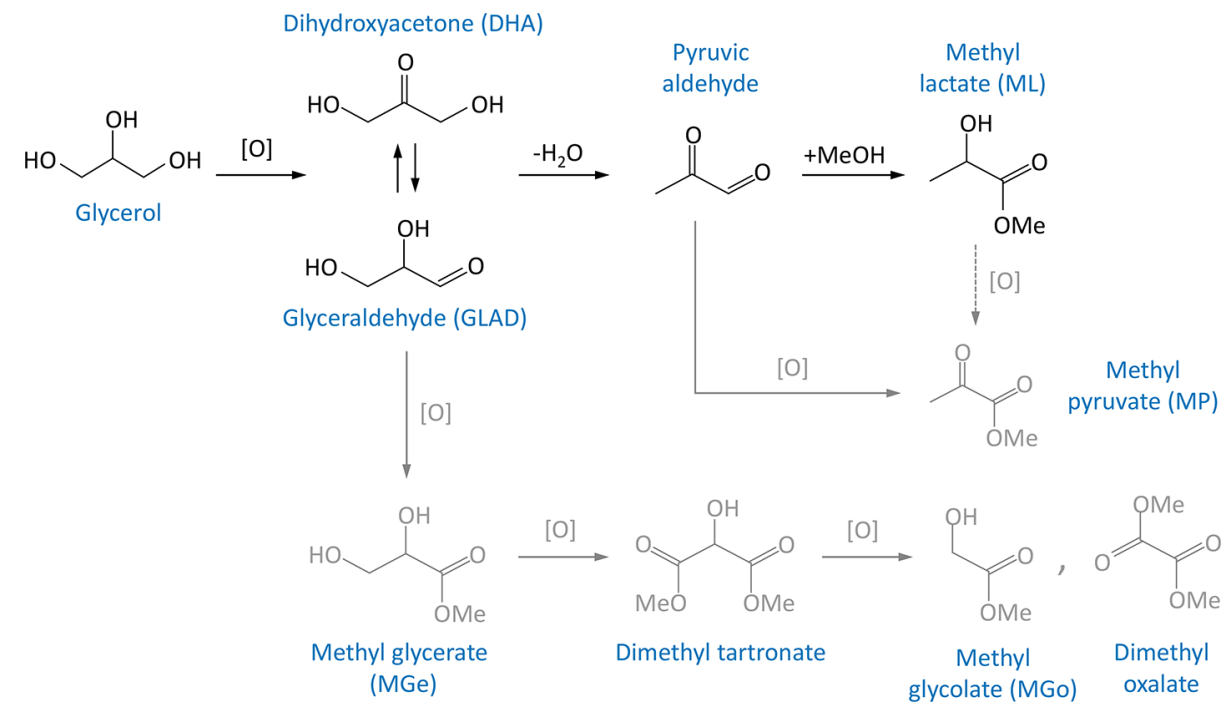

salt as product, which then requires further acidification/ neutralization and separation steps to be converted into lactic acid. This increases the cost of the process and generates a salt waste. In this context, developing active, selective, stable and fully heterogeneous catalytic systems for the production of lactic acid or lactates from glycerol is a timely and relevant target. So far, only a few studies have been dedicated to the synthesis of lactic acid or lactates from glycerol in base-free conditions. Au nanoparticles (NPs) supported on USY zeolite were the first base-free heterogeneous catalysts reported for the conversion of glycerol to methyl lactate (ML) in methanol. ${ }^{14}$ Recently, enhanced catalytic performance was achieved by incorporating $\mathrm{Sn}$ in a related $\mathrm{Au} / \mathrm{USY}$ zeolite system. ${ }^{12}$ The oxidation of glycerol to lactic acid in aqueous environment was achieved by using Pt NPs supported on zeolite Sn-MFI as bifunctional catalyst, giving $81 \%$ selectivity toward lactic acid at $90 \%$ conversion of glycerol under 6 bar $\mathrm{O}_{2}$ at relatively mild temperature $\left(100{ }^{\circ} \mathrm{C}\right) .^{16}$

The strategies that can be followed to overcome the challenge of selectively converting glycerol to lactic acid/ lactate without base involve (1) the use of noble metal catalysts under an oxidative atmosphere to catalyze the dehydrogenation step of glycerol to trioses (DHA and GLAD) and (2) the use of solid acids, containing both Lewis and mild Brønsted acid sites, to isomerize the intermediate trioses to lactic acid/alkyl lactate (Scheme 1). Noble metal catalysts (e.g., supported $\mathrm{Au}, \mathrm{Pt}, \mathrm{Pd}$, and their alloys) have been widely used to catalyze the oxidation of glycerol not only to trioses but also to glyceric acid and other carboxylic acids. ${ }^{4}$ The challenge is to control the degree of oxidation of glycerol to form selectively trioses since these intermediates can be easily oxidized further, leading to the formation of highly oxidized compounds as the main products (gray compounds in Scheme 1). ${ }^{5,6}$ For the rearrangement of triose to lactate, many studies have shown that solid acids, such as Sn-MCM-41, Sn-Beta, and USY zeolite, can serve as efficient isomerization catalysts. ${ }^{18-23}$ It is important to transform the intermediates fast and selectively since the lactic acid/alkyl lactate is much more stable than the trioses under the reaction conditions. ${ }^{14,16,24}$ Therefore, it is crucial to design carefully the noble metals and solid acid functions of the catalytic system but also to tune their relative amount.
Here, two novel multifunctional base-free catalytic systems were designed and investigated to maximize the synthesis of ML from glycerol: (1) Au NPs directly supported on a solid acid (extra small Sn-MCM-41 particles) and (2) a physical mixture consisting of $\mathrm{Au}$ NPs supported on various metal oxides and of extra-small Sn-MCM-41 particles (50-120 nm, Sn-MCM-41-XS). The reaction was carried out in methanol, which acts both as solvent and reactant. Methanol was selected instead of water for two reasons: (1) Methanol is much less corrosive than water for silica-based solid acids. (2) The products can be easily separated by distillation without requiring the esterification step employed in the current lactic acid production process. ${ }^{25}$

\section{EXPERIMENTAL SECTION}

Reactants and Materials. Glycerol (99\%), 1,3-dihydroxyacetone dimer (97\%), glyceraldehyde (90\%), methyl glycolate (98\%), methyl lactate $(98 \%)$, pyruvic aldehyde $\left(40\right.$ wt $\%$ in $\mathrm{H}_{2} \mathrm{O}$ ), tartronic acid (97\%), gold(III) chloride hydrate (99.999\%), poly(vinyl alcohol) (PVA, MW 9000-10000, 80\% hydrolyzed), sodium borohydride (99\%), cetyltrimethylammonium bromide (CTAB, 99\%), tetraethyl orthosilicate (TEOS, 98\%), tin chloride pentahydrate $\left(\mathrm{SnCl}_{4} \cdot 5 \mathrm{H}_{2} \mathrm{O}\right.$, $98 \%$ ), urea (99.5\%), copper oxide, zinc oxide, zirconium oxide, titanium oxide (P25), and niobium oxide were purchased from SigmaAldrich. Hydrotalcite $(\mathrm{HT}, \mathrm{Mg} / \mathrm{Al}=2$ ) was kindly provided by Kisuma Chemicals BV. USY zeolite $(\mathrm{CBV} 600, \mathrm{Si} / \mathrm{Al}=2.6)$ was purchased from Zeolyst. Glyceric acid (20 wt \% in $\mathrm{H}_{2} \mathrm{O}$ ) was purchased from TCI Chemicals. The $\mathrm{H}_{2} \mathrm{O}$ used in this work was always of Milli-Q grade. All chemicals were used without further purification.

Synthesis of Catalysts. Sn-MCM-41 nanoparticles (Sn-MCM41-XS) were synthesized according to a previously reported method. ${ }^{21}$ Briefly, $\mathrm{NaOH}$ aqueous solution $(2 \mathrm{M}, 3.6 \mathrm{~mL})$ was added to a solution of cetyltrimethylammonium bromide (CTAB, 1.0 $\mathrm{g})$ in $\mathrm{H}_{2} \mathrm{O}(480 \mathrm{~mL})$, after which the mixture was stirred vigorously at room temperature for $30 \mathrm{~min}$. Tetraethyl orthosilicate (TEOS, $2.29 \mathrm{~g}$ ) was added dropwise to the solution. Then, a solution of $\mathrm{SnCl}_{4} \cdot 5 \mathrm{H}_{2} \mathrm{O}$ in ethanol $(0.3 \mathrm{M}, 1 \mathrm{~mL})$ was added dropwise, after which more TEOS $(2.29 \mathrm{~g})$ was added dropwise. After stirring the mixture at room temperature for $2 \mathrm{~h}$, the slurry was filtered and washed three times with $\mathrm{H}_{2} \mathrm{O}(10 \mathrm{~mL})$ and then with ethanol $(10 \mathrm{~mL})$. The white solid was dried at $70{ }^{\circ} \mathrm{C}$ overnight, and the resulting powder was calcined at $550{ }^{\circ} \mathrm{C}$ in air for $5 \mathrm{~h}$, with a heating rate of $3{ }^{\circ} \mathrm{C} / \mathrm{min}$. The molar ratio in the synthesis of the sample was 1 TEOS:0.0135 $\mathrm{SnCl}_{4}$. $5 \mathrm{H}_{2} \mathrm{O}: 0.33 \mathrm{NaOH}: 0.125$ CTAB:0.9 EtOH: $1247 \mathrm{H}_{2} \mathrm{O}$. 
The Au NPs supported on metal oxides were prepared by the deposition-precipitation (DP) method in urea solution. ${ }^{26}$ The catalysts with 0.5 wt \% loading of Au NPs were prepared according to the same procedure using different supports: $\mathrm{CuO}, \mathrm{ZnO}, \mathrm{ZrO}_{2}$, $\mathrm{TiO}_{2}, \mathrm{Nb}_{2} \mathrm{O}_{5}, \mathrm{Al}_{2} \mathrm{O}_{3}$, and hydrotalcite (HT). For each catalyst, urea $(2.44 \mathrm{~g})$ and the support $(1.00 \mathrm{~g})$ were mixed in $\mathrm{H}_{2} \mathrm{O}(50 \mathrm{~mL})$, to which an aqueous solution of $\mathrm{HAuCl}_{4}(5 \mathrm{mg} \mathrm{Au}$ in $1.35 \mathrm{~mL}$ of aqueous solution) was added while stirring. The flask was fully covered with aluminum foil to protect from light and then continuously stirred at $80{ }^{\circ} \mathrm{C}$ for $6 \mathrm{~h}$. Next, the suspension was stirred at room temperature for extra $12 \mathrm{~h}$ and then washed thoroughly with Milli- $\mathrm{Q}$ water on a Buchner filter. The obtained catalyst was dried at $100{ }^{\circ} \mathrm{C}$ for $6 \mathrm{~h}$ and thermally treated at $200{ }^{\circ} \mathrm{C}$ in flowing air for $5 \mathrm{~h}$ in a quartz tubular oven. The obtained catalysts are denoted as $0.5 \mathrm{Au} / \mathrm{CuO}, 0.5 \mathrm{Au} / \mathrm{ZnO}, 0.5 \mathrm{Au} / \mathrm{ZrO}_{2}, 0.5 \mathrm{Au} / \mathrm{TiO}_{2}$, $0.5 \mathrm{Au} / \mathrm{Nb}_{2} \mathrm{O}_{5}, 0.5 \mathrm{Au} / \mathrm{Al}_{2} \mathrm{O}_{3}$, and $0.5 \mathrm{Au} / \mathrm{HT}$. The $\mathrm{Au} / \mathrm{CuO}$ catalysts were also prepared with different Au loading $(0.25,1,2 \mathrm{wt} \%)$ and by calcination at different temperatures in the range of $200-600{ }^{\circ} \mathrm{C}$, by straightforward adaptation of the procedure described above.

The DP method described above generates large Au NPs if SnMCM-41-XS was used as support. ${ }^{27}$ In order to decrease the Au particle size, another DP method was used in such case. ${ }^{28}$ In a typical synthesis, $10.8 \mathrm{mg} \mathrm{Au}(\mathrm{en})_{2} \mathrm{Cl}_{3}$ (gold(III) bis(ethylenediamine) chloride, which contains $5 \mathrm{mg} \mathrm{Au}$ ) was dissolved in $\mathrm{H}_{2} \mathrm{O}(50 \mathrm{~mL})$. The $\mathrm{pH}$ of the solution was then adjusted to 10.0 by $5.0 \mathrm{wt} \% \mathrm{NaOH}$ aqueous solution, and Sn-MCM-41-XS (1.0 g) was added. The $\mathrm{pH}$ was kept at 10.0 by adding $\mathrm{NaOH}$ solution. The suspension was stirred at $70{ }^{\circ} \mathrm{C}$ for $2 \mathrm{~h}$, then filtered and washed with $\mathrm{H}_{2} \mathrm{O}$. The lightyellow product was dried in vacuum at $70^{\circ} \mathrm{C}$ for $5 \mathrm{~h}$. The as-prepared catalyst was reduced in a flow of $4 \% \mathrm{H}_{2}$ (and $96 \% \mathrm{Ar}$ ) at $150{ }^{\circ} \mathrm{C}$ for 1 h. After cooling to room temperature, it was calcined in flowing $8 \%$ $\mathrm{O}_{2}$ (and $92 \% \mathrm{He}$ ) at $500{ }^{\circ} \mathrm{C}$ for $1 \mathrm{~h}$. The obtained catalyst is denoted as $0.5 \mathrm{Au} / \mathrm{Sn}-\mathrm{MCM}-41-\mathrm{XS} \mathrm{DP}$.

Au NPs supported on Sn-MCM-41-XS were prepared also using a colloidal immobilization (CI) method. ${ }^{29}$ A $3.5 \mathrm{~g} / \mathrm{L}$ aqueous solution of $\mathrm{HAuCl}_{4}(2.9 \mathrm{~mL})$ and a 2 wt \% aqueous solution of PVA $(1.2 \mathrm{~mL})$ were added to $\mathrm{H}_{2} \mathrm{O}(100 \mathrm{~mL})$, and the mixture was stirred for $30 \mathrm{~min}$. A freshly prepared aqueous solution of $\mathrm{NaBH}_{4}(0.1 \mathrm{M}, 2.54 \mathrm{~mL})$ was added dropwise to the mixture, which was then stirred for $30 \mathrm{~min}$. The $\mathrm{pH}$ was acidified to 2 by using $1 \mathrm{M}$ aqueous $\mathrm{H}_{2} \mathrm{SO}_{4}$. Sn-MCM41-XS ( $2 \mathrm{~g})$ was added to the solution, after which the suspension was stirred for $2 \mathrm{~h}$. The suspension was filtered, and the residue was washed with $2 \mathrm{~L}$ of $\mathrm{H}_{2} \mathrm{O}$ to neutralize the mixture and to remove PVA. The solid was dried overnight at $80{ }^{\circ} \mathrm{C}$. The obtained catalyst is denoted as $0.5 \mathrm{Au} / \mathrm{Sn}-\mathrm{MCM}-41-\mathrm{XS} \mathrm{CI}$.

Catalytic Tests. The catalytic tests were carried out in a $100 \mathrm{~mL}$ Parr stainless steel autoclave reactor equipped with a Teflon liner. In a typical test, a chosen amount of Au catalyst and of Sn-MCM-41-XS and a solution of glycerol in methanol $(0.25 \mathrm{M}, 20 \mathrm{~mL})$ were loaded into the reactor. The reaction was performed under $30 \mathrm{bar}$ air as oxidant for $4.5 \mathrm{~h}$ under vigorous mechanical stirring $(800 \mathrm{rpm})$, while heating to $140{ }^{\circ} \mathrm{C}$ (this temperature was reached in $0.5 \mathrm{~h}$, making the total length of test being $5 \mathrm{~h}$ ). Then, the reaction mixture was filtered to separate the catalyst and analyzed by gas chromatography (Thermo Trace GC) equipped with a Restek Stabilwax-DA column (30 m length, $0.32 \mathrm{~mm}$ ID, $1 \mu \mathrm{m} \mathrm{d}_{\mathrm{f}}$ ) and a FID detector. Each component was calibrated using the pure chemical, using four concentration points.

For the recyclability tests, a small amount of the reaction mixture was collected for analysis. The remaining mixture was filtered off, and the solid catalysts were recovered. The catalysts were washed first with $\mathrm{H}_{2} \mathrm{O}(20 \mathrm{~mL})$ and then with ethanol $(20 \mathrm{~mL})$. This procedure was repeated three times, after which the solid was dried overnight at 100 ${ }^{\circ} \mathrm{C}$.

Characterization of Catalysts. Transmission electron microscopy (TEM) images were obtained using an electron microscope CM12 (Philips) operating at $120 \mathrm{keV}$. Samples were prepared by ultrasonication in ethanol and dropping the suspension onto carboncoated 400 mesh copper grids. Images were taken with a slow scanning CCD camera. At least 100 nanoparticles were counted to obtain each particle size distribution histogram.

Nitrogen physisorption isotherms were measured at $-196{ }^{\circ} \mathrm{C}$ using a Micromeritics ASAP 2420 apparatus, which uses the BrunauerEmmet-Teller (BET) method to calculate the specific surface area and the Barrett-Joyner-Halenda $(\mathrm{BJH})$ method to calculate the pore size distribution.

Inductively coupled plasma optical emission spectrometry (ICPOES) was performed using a PerkinElmer Optima 7000 DV instrument in order to obtain the actual Au loadings on the supports, as well as the actual $\mathrm{Si} / \mathrm{Sn}$ ratio in Sn-MCM-41-XS. The measurements were performed using $17.5 \mathrm{mg}$ of the sample dissolved in $7 \mathrm{~mL}$ of $65 \%$ aqueous $\mathrm{HNO}_{3}, 1 \mathrm{~mL}$ of $36 \%$ aqueous $\mathrm{HCl}$, and $2 \mathrm{~mL}$ of $40 \%$ aqueous HF.

The UV-vis spectra were measured on a JASCO 570 UV-vis-NIR absorption spectrometer equipped with an integrating sphere.

The $0.5 \mathrm{Au} / \mathrm{CuO}$ and $0.5 \mathrm{Au} / \mathrm{TiO}_{2}$ catalysts were also analyzed by Fourier transform infrared spectroscopy (FT-IR) coupled to the adsorption/desorption of CO (at room temperature and $-196{ }^{\circ} \mathrm{C}$ ) and ethanol (at room temperature). The FT-IR spectra were performed on a Bruker Tensor 27 spectrometer equipped with a liquid nitrogen-cooled mercury-cadmium-telluride (MCT) detector, operating at $2 \mathrm{~cm}^{-1}$ resolution. Thin self-supporting wafers were prepared and submitted to a pretreatment using a standard vacuum frame (residual pressure $<10^{-3} \mathrm{mbar}$ ), in an IR cell equipped with $\mathrm{KBr}$ windows. Wafers were outgassed for $1 \mathrm{~h}$ at $400{ }^{\circ} \mathrm{C}$ before adsorption of $\mathrm{CO}$ or ethanol (in the pressure range 0.01-20.0 mbar). The reversible fraction of the adsorbate was then removed by prolonged outgassing at room temperature.

Definitions and Equations. Glycerol conversion (Conv./\%) is defined by the following equation:

$$
\text { Conv. }=\frac{C_{\mathrm{g}, 0}-C_{\mathrm{g}}}{C_{\mathrm{g}, 0}} \times 100 \%
$$

where $C_{\mathrm{g}, 0}$ is the initial concentration of glycerol, and $C_{\mathrm{g}}$ is the concentration of glycerol after a chosen reaction time.

Product selectivity for a compound $\mathrm{P}$ is defined by the following equation:

$$
S_{\mathrm{p}}=\frac{C_{\mathrm{p}}}{C_{\mathrm{g}, 0}-C_{\mathrm{g}}} \times 100 \%
$$

where $C_{\mathrm{p}}$ is the concentration of the product after a chosen reaction time.

The carbon balance $(\mathrm{C} / \%)$ was calculated as the sum of the percentage of unreacted glycerol plus the yields of all detected products (based on the concentrations quantified by GC).

\section{RESULTS AND DISCUSSION}

Two multifunctional, heterogeneous catalytic systems were designed and tested for the multistep conversion of glycerol into methyl lactate (ML). The first system consists of Au NPs directly supported on the Sn-MCM-41-XS by the depositionprecipitation (DP) or colloid-immobilization (CI) methods. The second system consists of a physical mixture of (1) Au nanoparticles supported on metal oxides $\left(\mathrm{Au} / \mathrm{MO}_{x}\right.$, with $\mathrm{MOx}$ being $\mathrm{CuO}, \mathrm{ZrO}_{2}, \mathrm{TiO}_{2}, \mathrm{Nb}_{2} \mathrm{O}_{5}, \mathrm{ZnO}$ ) or hydrotalcite (HT) and (2) a solid acid (Sn-MCM-41-XS or USY zeolite). In both systems, the $\mathrm{Au}$ nanoparticles are used as catalyst for the selective oxidation of glycerol, whereas Sn-MCM-41-XS (or USY) is chosen for catalyzing the consecutive rearrangement step (Scheme 1). Gold was chosen for catalyzing the partial oxidation of glycerol because it has been successfully used as a catalyst in the oxidation of hydroxyl groups to carbonyl groups in biobased substrates. ${ }^{30-32}$ Various metal oxides and hydrotalcite were investigated as support for the $\mathrm{Au}$ nanoparticles since the intrinsic properties of the support and its interaction 


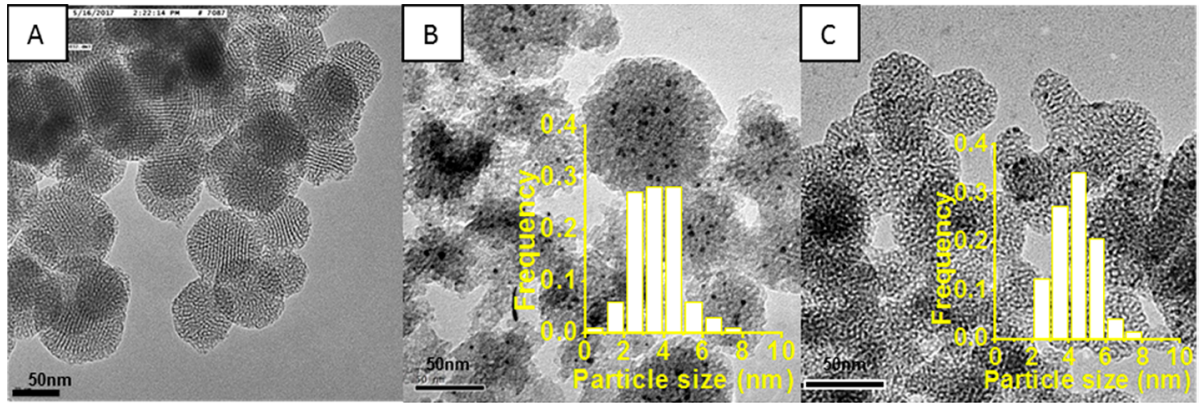

Figure 1. TEM images of Sn-MCM-41-XS (A) and of samples obtained by supporting Au NPs on Sn-MCM-41-XS by the DP method (B) or CI method (C).

Table 1. Physicochemical Properties of Selected Au Catalysts and Solid Acids ${ }^{a}$

\begin{tabular}{|c|c|c|c|c|c|}
\hline Entry & Catalyst & Au loading (wt \%) & Au average particle size $(\mathrm{nm})$ & $\mathrm{Sn} / \mathrm{Si}$ molar ratio & Surface area $\left(\mathrm{m}^{2} / \mathrm{g}\right)$ \\
\hline 1 & Sn-MCM-41-XS & n.a. & n.a. & $1 / 67$ & 1050 \\
\hline 2 & USY & n.a. & n.a. & n.a. & 552 \\
\hline 3 & $0.5 \mathrm{Au} / \mathrm{Sn}-\mathrm{MCM}-41-\mathrm{XS} \mathrm{DP}$ & 2.3 & 3.7 & $1 / 98$ & 640 \\
\hline 4 & $0.5 \mathrm{Au} / \mathrm{Sn}-\mathrm{MCM}-41-\mathrm{XS} \mathrm{CI}$ & 0.29 & 3.8 & $1 / 67$ & 926 \\
\hline 5 & $0.5 \mathrm{Au} / \mathrm{CuO}$ & 0.43 & 2.1 & n.a. & 3.0 \\
\hline
\end{tabular}

Table 2. Conversion of Glycerol to Methyl Lactate over Multifunctional Catalytic Systems Based on Supported Au Nanoparticles and Sn-MCM-41-XS ${ }^{a}$

\begin{tabular}{|c|c|c|c|c|c|c|c|c|}
\hline \multirow[b]{2}{*}{ Entry } & \multirow[b]{2}{*}{ Catalyst } & \multirow[b]{2}{*}{ Conv. $/ \%$} & \multirow[b]{2}{*}{ Yield of ML/\% } & \multicolumn{4}{|c|}{ Sel./\% } & \multirow[b]{2}{*}{$\mathrm{C} / \%$} \\
\hline & & & & ML & MGo & MGe & MP & \\
\hline 1 & $0.5 \mathrm{Au} / \mathrm{Sn}-\mathrm{MCM}-41-\mathrm{XS} \mathrm{DP}$ & 76 & 35 & 46 & 6.3 & 18 & 22 & 97 \\
\hline 2 & $0.5 \mathrm{Au} / \mathrm{Sn}-\mathrm{MCM}-41-\mathrm{XS} \mathrm{CI}$ & 20 & 16 & 82 & 7.6 & 3.7 & 0.4 & 99 \\
\hline 3 & $0.5 \mathrm{Au} / \mathrm{CuO}+\mathrm{Sn}-\mathrm{MCM}-41-\mathrm{XS}$ & 79 & 51 & 64 & 13 & 13 & 8.4 & 99 \\
\hline 4 & $0.5 \mathrm{Au} / \mathrm{CuO}+\mathrm{Sn}-\mathrm{MCM}-41-\mathrm{XS}^{b}$ & 95 & 63 & 66 & 11 & 8.5 & 7.2 & 95 \\
\hline 5 & $0.5 \mathrm{Au} / \mathrm{TiO}_{2}+\mathrm{Sn}-\mathrm{MCM}-41-\mathrm{XS}$ & 55 & 34 & 62 & 6.6 & 7.0 & 18 & 98 \\
\hline 6 & $0.5 \mathrm{Au} / \mathrm{ZrO}_{2}+\mathrm{Sn}-\mathrm{MCM}-41-\mathrm{XS}$ & 63 & 38 & 60 & 2.1 & 7.7 & 26 & 98 \\
\hline 7 & $0.5 \mathrm{Au} / \mathrm{Nb}_{2} \mathrm{O}_{5}+\mathrm{Sn}-\mathrm{MCM}-41-\mathrm{XS}$ & 57 & 35 & 61 & 4.8 & 0.4 & 9.7 & 93 \\
\hline 8 & $0.5 \mathrm{Au} / \mathrm{HT}+\mathrm{Sn}-\mathrm{MCM}-41-\mathrm{XS}$ & 52 & 21 & 41 & 11 & 16 & 8.3 & 92 \\
\hline 9 & $0.5 \mathrm{Au} / \mathrm{ZnO}+\mathrm{Sn}-\mathrm{MCM}-41-\mathrm{XS}$ & 76 & 21 & 27 & 7.3 & 3.3 & 2.6 & 76 \\
\hline
\end{tabular}

${ }^{a}$ Reaction conditions: temperature, $140{ }^{\circ} \mathrm{C}$; reaction time, $4.5 \mathrm{~h}$; glycerol amount, $0.25 \mathrm{M}$ in $20 \mathrm{~mL}$ methanol; air pressure, 30 bar; Au catalyst, 0.2 g (nominal Au/glycerol molar ratio of 1/985, assuming a 0.5 wt \% Au loading); Sn-MCM-41-XS, 0.2 g. ${ }^{b}$ Reaction time: 10 h.

with the Au nanoparticles can affect significantly the catalytic properties in glycerol oxidation. ${ }^{33,34}$ All $\mathrm{Au} / \mathrm{MO}_{x}$ catalysts were synthesized based on the DP method by using urea as the precipitating agent at $90{ }^{\circ} \mathrm{C}$.

Sn-MCM-41-XS, which has been reported as highly active and selective catalyst for the conversion of trioses to alkyl lactate, was synthesized based on a literature method. ${ }^{21}$ TEM images show that the nanoparticles constituting Sn-MCM-41XS have a relatively uniform size distribution in the range from 50 to $120 \mathrm{~nm}$, with an average size of around $70 \mathrm{~nm}$ and the characteristic well-ordered hexagonal array of mesopores (Figure 1A). $\mathrm{N}_{2}$ physisorption experiments indicated that $\mathrm{Sn}$ MCM-41-XS displays a large surface area of $1050 \mathrm{~m}^{2} / \mathrm{g}$ and the typical pore size distribution of MCM-41 materials centered at $2.5 \mathrm{~nm}$ (Table 1, entry 1 , and Figure S1). The pore size distribution of Sn-MCM-41-XS presents an additional broad peak centered at $50 \mathrm{~nm}$, ascribed to the voids between the $\mathrm{Sn}$ MCM-41 nanoparticles. A Si/Sn molar ratio of 67 was measured by ICP-OES, confirming the successful incorporation of $S n$ into the material (Table 1 , entry 1 ). Moreover, the diffuse reflectance UV-vis spectrum of Sn-MCM-41-XS (Figure S2) displays a main absorption at $208 \mathrm{~nm}$ that is ascribed to $\mathrm{Sn}(\mathrm{IV})$ species tetrahedrally coordinated within the silica framework. Such $\mathrm{Sn}(\mathrm{IV})$ species are known to act as Lewis acid sites with high activity in catalyzing the rearrangement of trioses to ethyl lactate. ${ }^{21}$ The UV-vis spectrum presents a shoulder peak at 250-280 nm that most likely originates from the overlapping of a signal at $245 \mathrm{~nm}$, attributed to either distorted tetrahedral and penta-coordinated framework $\mathrm{Sn}$ sites or small extra-framework $\mathrm{SnO}_{2}$ clusters, ${ }^{35,36}$ and a signal around $280 \mathrm{~nm}$, assigned to hexa-coordinated polymeric $\mathrm{Sn}-\mathrm{O}-\mathrm{Sn}$ species. ${ }^{37}$

Catalysts Consisting of Au Directly Supported on SnMCM-41-XS (Approach 1). Our initial strategy involved the preparation of a multifunctional catalyst in which the Au NPs are directly supported on the external surface (and preferably not within the pores) of Sn-MCM-41-XS, either using the DP method or the CI method. The catalyst $0.5 \mathrm{Au} / \mathrm{Sn}-\mathrm{MCM}-41$ XS prepared by the DP method showed high activity in glycerol conversion $(76 \%)$, but the selectivity toward methyl lactate was only $46 \%$, while the selectivity toward methyl pyruvate $(22 \%)$ and methyl glycerate $(18 \%)$ were relatively high (Table 2, entry 1 ). Methyl pyruvate can be produced by further oxidation of pyruvic aldehyde, and methyl glycerate is 
obtained by the further oxidation of glyceraldehyde (Scheme 1). ${ }^{5,17}$ This result indicates that the oxidation activity of the $\mathrm{Au} / \mathrm{Sn}-\mathrm{MCM}-41-\mathrm{XS}$ catalyst made by the DP method is much higher than its activity in the rearrangement. This can be related to the observed deterioration of the MCM-41structure upon the basic hydrothermal synthesis in the DP method (compare the TEM image in Figure 1B to pristine Sn-MCM41-XS in Figure 1A). Additionally, the ICP-OES results obtained for Au/Sn-MCM-41-XS DP (Table 1) show that the $\mathrm{Au}$ loading in this catalyst is $2.3 \mathrm{wt} \%$, which is considerably higher than the nominal value $(0.5 \mathrm{wt} \%)$ and that the $\mathrm{Sn} / \mathrm{Si}$ molar ratio $(1 / 98)$ is much lower than in the original $\mathrm{Sn}$ MCM-41-XS (1/67). These results are in agreement with the partial dissolution of the Sn-MCM-41-XS particles during the DP method in the hydrothermal basic solution, resulting in the loss of Sn sites and of part of the silica matrix, with a consequent decrease of Lewis acidity and increase of $\mathrm{Au}$ loading. The high loading of Au NPs (with average size of 3.7 $\mathrm{nm}$, see Figure 1B) and the partial loss of Sn sites as well as of the structure of Sn-MCM-41-XS explain why further oxidation of the trioses was favored over rearrangement with this catalyst. On the basis of these data and with the purpose of preserving the Sn-MCM-41-XS structure, the milder CI preparation method was then selected to synthesize $0.5 \mathrm{Au} / \mathrm{Sn}-\mathrm{MCM}-41$ XS CI. The obtained catalyst showed higher selectivity toward methyl lactate $(82 \%)$ but much lower conversion of glycerol (20\%) than Au/Sn-MCM-41-XS DP under the same reaction conditions (Table 2, entry 2). The Lewis acidity of Sn-MCM41-XS was preserved since the CI preparation did not involve a basic solution or hydrothermal treatment. On the other hand, the actual $\mathrm{Au}$ loading on $0.5 \mathrm{Au} / \mathrm{Sn}-\mathrm{MCM}-41-\mathrm{XS} \mathrm{CI}$ was significantly lower $(0.29 \mathrm{wt} \%)$ than the nominal loading $(0.5$ wt \%, Table 1), and the Au NPs were localized in small areas rather than homogeneously dispersed over the whole SnMCM-41-XS surface (see TEM image in Figure 1C). This is probably due to the weak interaction between the $\mathrm{Au}$ nanoparticle colloid and the surface of Sn-MCM-41-XS. The catalytic results of $\mathrm{Au} / \mathrm{Sn}-\mathrm{MCM}-41-\mathrm{XS} \mathrm{CI}$ reveal that the rearrangement activity was suitable, but the oxidation activity was not optimal. A comparison of the results obtained with the $0.5 \mathrm{Au} / \mathrm{Sn}-\mathrm{MCM}-41-\mathrm{XS}$ catalysts prepared by the DP or CI method highlights the challenge in achieving a good balance between oxidation and rearrangement activity of the catalyst when the Au nanoparticles are directly supported on the SnMCM-41-XS. Moreover, the nature of the support for $\mathrm{Au}$ nanoparticles can play a significant role as a part of the catalyst in the oxidation of glycerol, ${ }^{33,34}$ and other supports might lead to enhanced catalytic performance.

Catalytic Systems Consisting of Au NPs on Metal Oxides Combined with Sn-MCM-41-XS (Approach 2). To avoid the issues encountered when supporting the $\mathrm{Au}$ nanoparticles directly on Sn-MCM-41-XS, we decided to investigate a dual catalytic system consisting of a physical mixture of Sn-MCM-41-XS and of Au NPs supported on various commercially available metal oxides or on hydrotalcite (Table 2). The TEM images of these catalysts show that the $\mathrm{Au}$ NPs are well dispersed on all supports (Figure S3). The mean size of $\mathrm{Au}$ NPs ranges from $2.0 \mathrm{~nm}$ on $\mathrm{CuO}$ to $5.3 \mathrm{~nm}$ on $\mathrm{Nb}_{2} \mathrm{O}_{5}$, with a rather narrow size distribution in all cases. The multifunctional catalytic systems based on various $\mathrm{Au} / \mathrm{MO}_{x}$ in combination with Sn-MCM-41-XS were tested for the aerobic oxidation of glycerol at $140{ }^{\circ} \mathrm{C}$ and 30 bar air pressure. Methyl lactate $(\mathrm{ML})$ was the main product in most tests, with methyl pyruvate (MP), methyl glycolate (MGo), and methyl glycerate (MGe) as byproducts (Table 2). These methyl carboxylate byproducts are formed by overoxidation of reaction intermediates (Scheme 1). $0.5 \mathrm{Au} / \mathrm{CuO}$ with $\mathrm{Sn}-\mathrm{MCM}-41-\mathrm{XS}$ showed the highest yield of ML (51\%) by combining the highest glycerol conversion (79\%) and the highest ML selectivity (64\%) after 4.5 h reaction (Table 2 , entry 3 ). The carbon balance was $99 \%$, which indicates that neither gas phase components (like $\mathrm{CO}_{2}$ ) nor condensation products with higher molecular weight were formed. After $10 \mathrm{~h}$ of reaction, the conversion of glycerol reached $95 \%$ with $63 \%$ yield of ML (Table 2, entry 4). The catalysts in which Sn-MCM-41-XS was combined with $0.5 \mathrm{Au} / \mathrm{TiO}_{2}, 0.5 \mathrm{Au} / \mathrm{ZrO}_{2}$, or $\mathrm{Au} / \mathrm{Nb}_{2} \mathrm{O}_{5}$ displayed only slightly lower selectivity toward ML (60$62 \%)$, though at a significantly lower glycerol conversion and thus lower yield of ML (35\% to 38\%) (Table 2, entries 5-7). On the other hand, with $0.5 \mathrm{Au} / \mathrm{HT}$ or $0.5 \mathrm{Au} / \mathrm{ZnO}$ (Table 2, entries 8 and 9), the total selectivity to carboxylic acid esters originating from the overoxidation was higher than that toward ML. This means that the Au catalysts were too active and that the products of the first oxidation step (from glycerol to trioses) were further oxidized rather than undergoing rearrangement over Sn-MCM-41-XS to form ML. Methyl pyruvate was the main byproduct, which is probably formed by further oxidation of pyruvic aldehyde (or methyl lactate). As discussed above, most of the byproducts are formed by overoxidation of the intermediates, such as GLAD, DHA, and pyruvic aldehyde, before being converted to ML. In all cases, the oxidation of methanol did not compete significantly with the oxidation of glycerol ${ }^{14,38}$ as proven by the low amount of formaldehyde formed during the reaction (less than $1 \%$ yield relative to methanol).

It should be noted that catalysts presenting very similar $\mathrm{Au}$ particle size, for example, $0.5 \mathrm{Au} / \mathrm{CuO}$ and $0.5 \mathrm{Au} / \mathrm{ZnO}$ (Figure S3), displayed a large difference in catalytic performance (Table 2). On the other hand, $0.5 \mathrm{Au} / \mathrm{TiO}_{2}$ and $0.5 \mathrm{Au} / \mathrm{Nb}_{2} \mathrm{O}_{5}$ exhibited similar catalytic results (Table 2), although they have quite different $\mathrm{Au}$ particle size (Figure S3). These observations suggest that the support plays a more important role than the $\mathrm{Au}$ particle size on the performance of the catalysts in the conversion of glycerol to methyl lactate. The influence of the support on the behavior of the catalytic system is most likely related to the occurrence of strong interactions between the surface of the support and the reaction intermediates, which hamper desorption and thus increase the possibility for overoxidation reactions.

FT-IR Study of Adsorbed Probe Molecules. With the purpose of getting further insight into the catalytic performance of the Au-supported catalysts and to achieve a deeper understanding concerning the role of the oxide support, a comparative FT-IR study of adsorbed probe molecules was performed on two selected systems, $0.5 \mathrm{Au} / \mathrm{CuO}$ and $0.5 \mathrm{Au} /$ $\mathrm{TiO}_{2}$, by using $\mathrm{CO}$ and ethanol as adsorbates. In the literature, FT-IR spectroscopy of adsorbed CO has been widely used to characterize the nature of gold species on Au-supported catalysts. This technique allows the identification of the oxidation state of surface gold sites, ${ }^{39,40}$ as cationic and metallic sites can be discriminated on the basis of the frequency and stability upon outgassing of the surface carbonyl species formed after CO adsorption. Moreover, the possible catalytic role of the support can be characterized, as CO is able to interact with uncoordinated cationic sites acting as Lewis acid sites. On the other hand, ethanol was selected as a model 

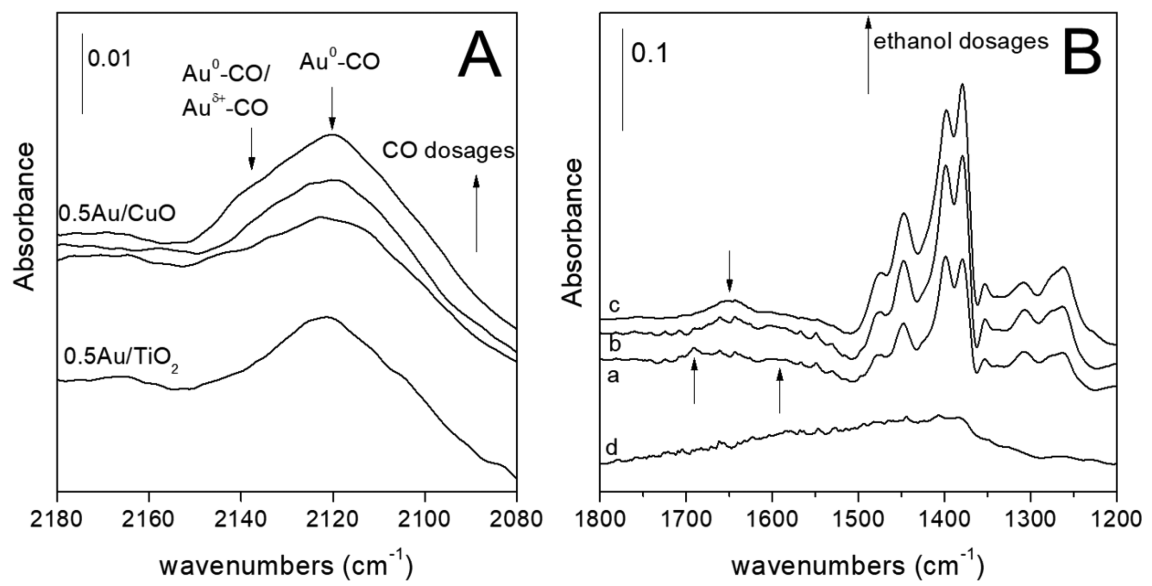

Figure 2. FT-IR spectra of $\mathrm{CO}(\mathrm{A})$ and ethanol (B) adsorbed on $0.5 \mathrm{Au} / \mathrm{CuO}$ and $0.5 \mathrm{Au} / \mathrm{TiO}_{2}$, outgassed at $400{ }^{\circ} \mathrm{C}$.

molecule for glycerol to investigate the adsorption and the possible reactivity of a low-molecular weight alcohol on the supported $\mathrm{Au}$ catalysts at room temperature.

Figure $2 \mathrm{~A}$ shows the dosages of increasing equilibrium pressures of $\mathrm{CO}$ on $0.5 \mathrm{Au} / \mathrm{CuO}$ after outgassing at $400{ }^{\circ} \mathrm{C}$. A broad composite absorption band was observed at around $2120 \mathrm{~cm}^{-1}$, with faintly discernible shoulders at around 2132 and $2140 \mathrm{~cm}^{-1}$. The signal at lower frequency is ascribed to a $\mathrm{CO}$ molecule coordinated to metallic gold species $\left(\mathrm{Au}^{0}-\mathrm{CO}\right)$, whereas the bands at higher frequencies are assigned to $\mathrm{CO}$ adsorbed on $\mathrm{Au}^{0}$ sites in defects (coordinatively unsaturated sites) or on $\mathrm{Au}$ sites with a partial positive charge $\left(\mathrm{Au}^{\delta+}\right){ }^{41}$ Coordination of $\mathrm{CO}$ to all $\mathrm{Au}$ sites proved reversible upon prolonged outgassing at room temperature. No bands due to $\mathrm{CO}-\mathrm{Au}^{3+}$ species were observed in their characteristic 2176$2168 \mathrm{~cm}^{-1}$ range, suggesting that most gold is in the reduced state. The role of the $\mathrm{CuO}$ support in the adsorption of $\mathrm{CO}$ was negligible, as the spectra do not show bands ascribable to the interaction with $\mathrm{Cu}^{2+}$ or $\mathrm{Cu}^{+}$species formed upon reduction by $\mathrm{CO}{ }^{42}$ The FT-IR spectra of $\mathrm{CO}$ adsorbed on $0.5 \mathrm{Au} / \mathrm{TiO}_{2}$ outgassed at $400{ }^{\circ} \mathrm{C}$ showed very similar carbonyl bands, although slightly less intense, suggesting gold surface sites with comparable strength to those observed for $0.5 \mathrm{Au} /$ $\mathrm{CuO}$. The adsorption of $\mathrm{CO}$ was also monitored at the nominal temperature of $-196{ }^{\circ} \mathrm{C}$ to investigate the interaction with the oxide supports. No significant difference compared to the measurement at room temperature was observed with $\mathrm{Au} /$ $\mathrm{CuO}$, whereas the typical bands ascribed to carbonyl on Lewis acid sites were observed with $\mathrm{Au} / \mathrm{TiO}_{2}$. In particular, the main band at around $2187 \mathrm{~cm}^{-1}$ is assigned to $\beta-\mathrm{Ti}^{4+}$ sites, and the band of lower intensity at around $2206 \mathrm{~cm}^{-1}$ is due to a small fraction of $\mathrm{CO}$ coordinated to $\alpha-\mathrm{Ti}^{4+}$ sites, the most acidic Lewis acid sites, generated during evacuation at ca. $300{ }^{\circ} \mathrm{C}$. This attests the role of the $\mathrm{TiO}_{2}$ support alone in providing active Lewis acid centers. ${ }^{41}$

The adsorption of ethanol, chosen as model alcohol molecule, was carried out on both samples outgassed at 400 ${ }^{\circ} \mathrm{C}$ (Figure 2B). No significant absorption bands appeared after the dosage of ethanol at room temperature on $0.5 \mathrm{Au} / \mathrm{CuO}$, apart from the signals of the molecule in the vapor phase, suggesting a negligible interaction with the supported Au NPs and the support alone. On the other hand, the addition of ethanol on $0.5 \mathrm{Au} / \mathrm{TiO}_{2}$ led to the appearance of several bands (Figure 2B). The bands at 1474, ca. 1400 and $1354 \mathrm{~cm}^{-1}$ are ascribed to the formation of surface ethoxy species, which are generally considered the primary step in alcohol activation. It has been reported that on $\mathrm{TiO}_{2}$-based oxidation catalysts an acetaldehyde intermediate is produced transiently from the reaction of ethanol/ethoxide and is considered the source for the formation of adsorbed acetyl and acetate species. ${ }^{43}$ With the $\mathrm{Au} / \mathrm{TiO}_{2}$ catalyst, the weak signal at around $1690 \mathrm{~cm}^{-1} \mathrm{can}$ be attributed to an adsorbed aldehyde intermediate, which gets partially oxidized to an acetyl group $\left(\mathrm{CH}_{3} \mathrm{CO}\right)$, as revealed by the band at $1645 \mathrm{~cm}^{-1}$. The latter is the precursor for the acetate species, absorbing at 1448 and $1541-1545 \mathrm{~cm}^{-1}$. The weak band at $1585 \mathrm{~cm}^{-1}$ is assigned to the formation of low amounts of adsorbed formate (HCOO). The $1269 \mathrm{~cm}^{-1}$ band is attributed to the $\delta(\mathrm{OH})$ mode of molecularly adsorbed ethanol. ${ }^{43}$ All the cited signals are stable upon prolonged outgassing at room temperature, demonstrating a stronger interaction between the adsorbates and the sites at the surface of $\mathrm{Au} / \mathrm{TiO}_{2}$ compared to those on $\mathrm{Au} / \mathrm{CuO}$.

TEM characterization combined with the results of the adsorption of $\mathrm{CO}$ and ethanol on $\mathrm{Au} / \mathrm{CuO}$ and $\mathrm{Au} / \mathrm{TiO}_{2}$ indicate that both materials contain well-dispersed metallic $\mathrm{Au}$ nanoparticles. However, the behavior of the oxide used as support is different in the two catalysts. The observed difference in the adsorption of ethanol on $\mathrm{Au} / \mathrm{TiO}_{2}$ compared to $\mathrm{Au} / \mathrm{CuO}$ can explain the different side product selectivity over the two catalysts (Table 2, entries 3 and 5). On $\mathrm{Au} / \mathrm{TiO}_{2}$, the formed trioses (DHA and GLAD) would have a higher tendency to remain adsorbed and thus to dehydrate to pyruvic aldehyde, because of the acidity on the $\mathrm{TiO}_{2}$, and then get overoxidized to methyl pyruvate (Scheme 1). On the other hand, the weak interaction between the reaction intermediates and $\mathrm{Au} / \mathrm{CuO}$ is probably beneficial for the desorption of the trioses and their diffusion to the Sn-MCM-41-XS catalyst over which they get rearranged into the desired methyl lactate product. These results reveal that the interaction between substrate and support can largely affect the behavior of the catalytic system.

Optimization Studies Using Au/CuO and Sn-MCM-41XS. Since the $\mathrm{Au} / \mathrm{CuO}$ catalyst combined with Sn-MCM-41$\mathrm{XS}$ showed the most promising results in terms of activity and selectivity toward methyl lactate, this system was investigated further by varying the loading of $\mathrm{Au}$ NPs on the $\mathrm{CuO}$ support from 0.25 to 2 wt \%, while keeping constant the amount of $\mathrm{Sn}$ MCM-41-XS. The same nominal amount of $\mathrm{Au}(1 \mathrm{mg}$, corresponding to a Au/glycerol molar ratio of 1/985) was used in each catalytic test. The actual loading was slightly lower than 
Table 3. Catalytic Performance in The Conversion of Glycerol into Methyl Lactate over Catalytic System Consisting of Au/ $\mathrm{CuO}$ and Sn-MCM-41-XS, as a Function of Au Loading in $\mathrm{Au} / \mathrm{CuO}^{a}$

\begin{tabular}{|c|c|c|c|c|c|c|c|c|c|c|}
\hline \multirow[b]{2}{*}{ Entry } & \multirow[b]{2}{*}{ Catalyst } & \multirow[b]{2}{*}{ Au loading $/ \%$} & \multirow[b]{2}{*}{$\mathrm{TOF} / \mathrm{h}^{-1}$} & \multirow[b]{2}{*}{ Conv./\% } & \multirow[b]{2}{*}{ Yield of ML/\% } & \multicolumn{4}{|c|}{ Sel./\% } & \multirow[b]{2}{*}{$\mathrm{C} / \%$} \\
\hline & & & & & & ML & MGo & $\mathrm{MGe}$ & MP & \\
\hline 1 & $0.25 \mathrm{Au} / \mathrm{CuO}+\mathrm{Sn}-\mathrm{MCM}-41-\mathrm{XS}$ & 0.21 & 174 & 67 & 40 & 60 & 16 & 12 & 3.6 & 99 \\
\hline 2 & $0.5 \mathrm{Au} / \mathrm{CuO}+\mathrm{Sn}-\mathrm{MCM}-41-\mathrm{XS}$ & 0.43 & 201 & 79 & 51 & 64 & 13 & 13 & 8.4 & 99 \\
\hline 3 & $1 \mathrm{Au} / \mathrm{CuO}+\mathrm{Sn}-\mathrm{MCM}-41-\mathrm{XS}$ & 0.78 & 208 & 74 & 46 & 62 & 11 & 11 & 8.9 & 98 \\
\hline 4 & $2 \mathrm{Au} / \mathrm{CuO}+\mathrm{Sn}-\mathrm{MCM}-41-\mathrm{XS}$ & 1.79 & 161 & 66 & 45 & 68 & 12 & 9 & 5.3 & 98 \\
\hline
\end{tabular}

${ }^{a}$ Reaction conditions: temperature, $140{ }^{\circ} \mathrm{C}$; reaction time, $4.5 \mathrm{~h}$; glycerol amount, $0.25 \mathrm{M}$ in $20 \mathrm{~mL}$ methanol; air pressure, 30 bar; Sn-MCM-41$\mathrm{XS}, 0.2 \mathrm{~g}$; in all tests, the theoretical amount of Au was kept constant at $1 \mathrm{mg}$ (nominal Au/glycerol molar ratio of 1/985). TOF is defined as moles of glycerol converted per $\mathrm{h}$ per mole of $\mathrm{Au}$ (as determined by ICP-OES).

the preset value (Table 3 ), probably due to the uncertainty in the content of $\mathrm{Au}\left(45-55\right.$ wt \%) in the source $\mathrm{HAuCl}_{4} \cdot \mathrm{xH}_{2} \mathrm{O}$ and/or to the incomplete precipitation of Au species with the DP method. It should be noted that the particle size slightly changed when the loading increased from 0.25 to $1 \mathrm{wt} \%$ (from 1.9 to $2.2 \mathrm{~nm}$ ), and when the loading reached $2 \mathrm{wt} \%$, the mean Au particle size increased to $3.2 \mathrm{~nm}$, as determined by TEM images (Figure 3). This trend is ascribed to the limited

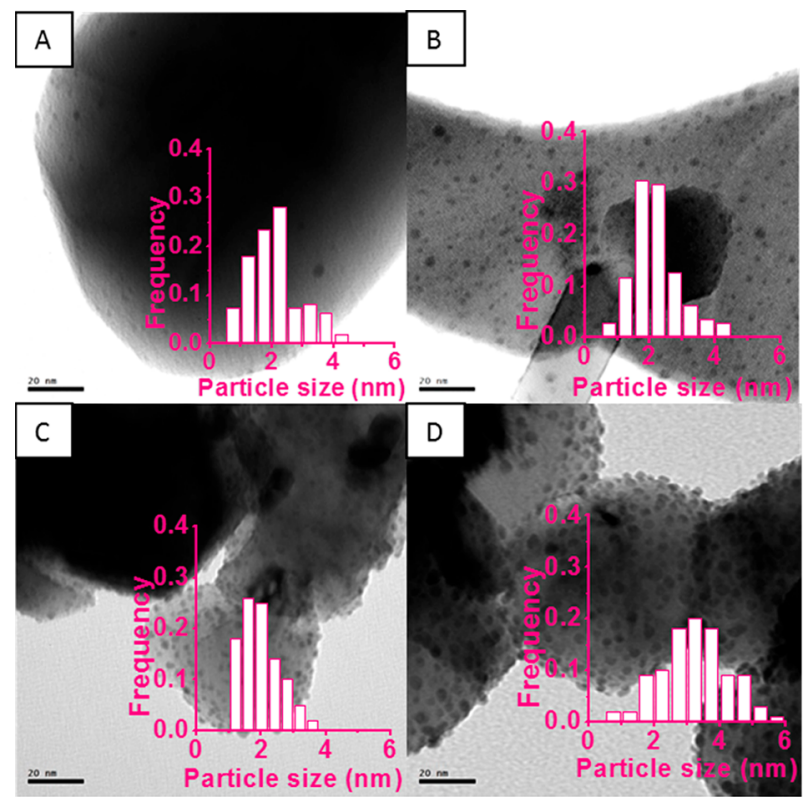

Figure 3. TEM images of $\mathrm{Au}$ supported on $\mathrm{CuO}$ with different $\mathrm{Au}$ loadings: (A) $0.25 \mathrm{Au} / \mathrm{CuO}$, average $\mathrm{Au}$ particle size $=1.9 \mathrm{~nm},(\mathrm{~B})$ $0.5 \mathrm{Au} / \mathrm{CuO}$, average $\mathrm{Au}$ particle size $=2.1 \mathrm{~nm},(\mathrm{C}) 1 \mathrm{Au} / \mathrm{CuO}$, average $\mathrm{Au}$ particle size $=2.2 \mathrm{~nm}$, and $(\mathrm{D}) 2 \mathrm{Au} / \mathrm{CuO}$, average $\mathrm{Au}$ particle size $=3.2 \mathrm{~nm}$. The scale bar is $20 \mathrm{~nm}$ in all cases.

surface area of $\mathrm{CuO}$ (around $3 \mathrm{~m}^{2} / \mathrm{g}$, see Table 1 ), as suggested by the decreased average distance between Au NPs in the material prepared with 2 wt \% Au loading (Figure 3D). The $\mathrm{Au} / \mathrm{CuO}$ materials with different $\mathrm{Au}$ loading were tested with Sn-MCM-41-XS as catalysts for the synthesis of methyl lactate from glycerol (Table 3). Since the nominal and actual loading differ slightly, the turnover frequency (TOF) was calculated and used together with conversion data to interpret the activity of these $\mathrm{Au} / \mathrm{CuO}$ catalysts (Table 3). The TOF increased from 174 to 208 by increasing the loading from $0.25 \%$ to $1 \%$, and then decreased to 161 with the $2 \% \mathrm{Au}$ loading. The selectivity to methyl lactate increased from $60 \%$ to $68 \%$ with the increase in loading from $0.25 \%$ to $2 \%$. This is coupled to a decrease in the total selectivity of overoxidative byproducts from $35 \%$ to $26 \%$ (Table 3 ). The decrease in TOF, decrease in byproducts selectivity, and increase in methyl lactate selectivity with the highest Au loading on $\mathrm{CuO}$ can be correlated well with the larger size of Au NPs (from $\sim 2 \mathrm{~nm}$ up to $1.0 \% \mathrm{Au}$ loading to $3.2 \mathrm{~nm}$ for $2.0 \% \mathrm{Au}$ loading, Figure 2). On one hand, larger Au particles exhibit lower activity (lower fraction of exposed Au atoms), which leads to lower TOF. On the other hand, the large size of the particles also implies a lower fraction of $\mathrm{Au}$ atoms with lower coordination (e.g., at corner and step sites) that might be responsible for the overoxidation of the key intermediates (i.e., GLAD and DHA), thus limiting these side reactions and increasing the selectivity toward methyl lactate.

The catalytic system based on $\mathrm{Au} / \mathrm{CuO}$ was investigated further by screening the effect of the calcination temperature on the size of the Au nanoparticles. This study was carried out on the $\mathrm{Au} / \mathrm{CuO}$ with 1 wt \% Au loading. The average size of $\mathrm{Au}$ NPs, which was calculated based on the TEM images, gradually increased from 2.2 to $10 \mathrm{~nm}$ by increasing the calcination temperature from 200 to $600{ }^{\circ} \mathrm{C}$. This trend matches the expected tendency of Au NPs to aggregate at higher temperature. This series of $1 \mathrm{Au} / \mathrm{CuO}$ catalysts was then tested in combination with Sn-MCM-41-XS (Figure 4). Clear

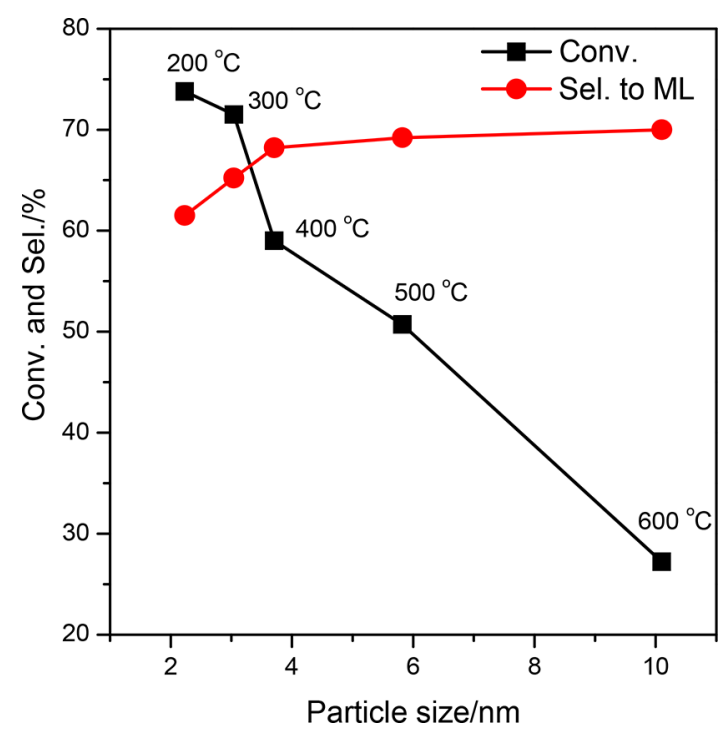

Figure 4. Catalytic performance in the conversion of glycerol into methyl lactate over the catalytic system consisting of $1 \mathrm{Au} / \mathrm{CuO}$ and $\mathrm{Sn}-\mathrm{MCM}-41-\mathrm{XS}$, as a function of the temperature at which $1 \mathrm{Au} / \mathrm{CuO}$ was calcined. Reaction conditions: temperature, $140{ }^{\circ} \mathrm{C}$; reaction time, $4.5 \mathrm{~h}$; glycerol amount, $0.25 \mathrm{M}$ in $20 \mathrm{~mL}$ methanol; air pressure, $30 \mathrm{bar} ; 1 \mathrm{Au} / \mathrm{CuO}$ catalyst, $0.1 \mathrm{~g}$; Sn-MCM-41-XS, $0.2 \mathrm{~g}$. 
Table 4. Catalytic Performance in The Conversion of Glycerol into Methyl Lactate over the Catalytic System Consisting of $\mathrm{Au} / \mathrm{CuO}$ and Sn-MCM-41-XS, as a Function of The Relative Loading of Sn-MCM-41-XS

\begin{tabular}{|c|c|c|c|c|c|c|c|c|c|}
\hline \multirow[b]{2}{*}{ Entry } & \multirow[b]{2}{*}{ Catalyst } & \multirow[b]{2}{*}{ Mass of Sn-MCM-41-XS/g } & \multirow[b]{2}{*}{ Conv. $/ \%$} & \multirow[b]{2}{*}{ Yield of ML/\% } & \multicolumn{4}{|c|}{ Sel./\% } & \multirow[b]{2}{*}{$\mathrm{C} / \%$} \\
\hline & & & & & ML & MGo & MGe & MP & \\
\hline 1 & $2 \mathrm{Au} / \mathrm{CuO}+\mathrm{Sn}-\mathrm{MCM}-41-\mathrm{XS}$ & 0.1 & 56 & 35 & 62 & 12 & 10 & 5.6 & 94 \\
\hline 2 & $2 \mathrm{Au} / \mathrm{CuO}+\mathrm{Sn}-\mathrm{MCM}-41-\mathrm{XS}$ & 0.2 & 66 & 45 & 68 & 12 & 9 & 5.3 & 98 \\
\hline 3 & $2 \mathrm{Au} / \mathrm{CuO}+\mathrm{Sn}-\mathrm{MCM}-41-\mathrm{XS}$ & 0.3 & 66 & 45 & 68 & 9 & 9 & 4.3 & 94 \\
\hline 4 & $2 \mathrm{Au} / \mathrm{CuO}+\mathrm{Sn}-\mathrm{MCM}-41-\mathrm{XS}$ & 0.4 & 54 & 40 & 74 & 10 & 9 & 3.7 & 98 \\
\hline
\end{tabular}

${ }^{a}$ Reaction conditions: temperature, $140{ }^{\circ} \mathrm{C}$; reaction time, $4.5 \mathrm{~h}$; glycerol amount, $0.25 \mathrm{M}$ in $20 \mathrm{~mL}$ methanol; air pressure, 30 bar; Au catalyst, 0.05 g (nominal Au/glycerol molar ratio of 1/985).

trends were observed as a function of the average Au particle size. By increasing the Au particle size from 2.2 to $10 \mathrm{~nm}$, the TOF of glycerol gradually decreased from 208 to $77 \mathrm{~h}^{-1}$ (glycerol conversion from $74 \%$ to $27 \%$ ), and the selectivity toward methyl lactate gradually increased from $62 \%$ to $70 \%$. The steep drop in activity is ascribed to the increasing diameter of the $\mathrm{Au}$ particle, which significantly reduces the fraction of $\mathrm{Au}$ atoms that are exposed on the surface. The effect of the particle size on the selectivity toward methyl lactate is less dramatic, as the selectivity increases from $62 \%$ to $68 \%$ when the $\mathrm{Au}$ particle size grows from 2.2 to $3.7 \mathrm{~nm}$, and then increases only $2 \%$ as the average Au particle size goes from 3.7 to $10 \mathrm{~nm}$. Similar to what discussed for the effect of the $\mathrm{Au}$ loading, the increase in selectivity is correlated to the decreased overoxidation activity. In this series of $\mathrm{Au} / \mathrm{CuO}$ catalysts, the highest yield of methyl lactate $(47 \%$ at $72 \%$ glycerol conversion, $1 \mathrm{Au} / \mathrm{CuO}$ calcined at $300{ }^{\circ} \mathrm{C}$ ) can be obtained when the $\mathrm{Au}$ particle size is around $3 \mathrm{~nm}$, which can be considered as the optimal balance between activity and selectivity of the $\mathrm{Au} / \mathrm{CuO}$ catalyst.

Effect of Nature and Amount of Solid Acid Catalyst. Besides screening and tuning the properties of the $\mathrm{Au} / \mathrm{CuO}$ catalyst used in the oxidation of glycerol, we investigated the performance of a USY zeolite (CBV 600, $\mathrm{Si} / \mathrm{Al}=2.6)$ as the solid acid instead of Sn-MCM-41-XS. This USY contains both framework and extra-framework $\mathrm{Al}$ species acting as Brønsted and Lewis acid sites, respectively, and has been reported as an efficient heterogeneous catalyst for the conversion of DHA to alkyl lactate. ${ }^{44}$ Accordingly, USY catalyzed the conversion of DHA to ethyl lactate with high activity and selectivity (Table S1, entry 1), although Sn-MCM-41-XS gave higher selectivity and yield of lactate under the same conditions (Table S1, Entry $2) .{ }^{44}$ When USY was used in combination with $0.5 \mathrm{Au} / \mathrm{CuO}$ in the conversion of glycerol to methyl lactate, a much inferior performance was observed compared to Sn-MCM-41-XS (Table S2, entries 1 and 2). The conversion of glycerol was $17 \%$ lower than over $0.5 \mathrm{Au} / \mathrm{CuO}$ with $\mathrm{Sn}-\mathrm{MCM}-41-\mathrm{XS}$, and the selectivity toward methyl lactate was only $8 \%$, compared to $64 \%$ selectivity when the solid acid was Sn-MCM-41-XS. The large difference in products distribution indicates that USY is not an efficient Lewis acid catalyst for the rearrangement when used in combination with $0.5 \mathrm{Au} / \mathrm{CuO}$. This may be caused by the predominant Brønsted nature of the acid sites of USY and by diffusion limitations in its micropores $(0.74 \mathrm{~nm}$ for the 12 membered rings), which are significantly narrower compared to the mesopores of Sn-MCM-41-XS. ${ }^{20}$ Compared to USY zeolite, Sn-MCM-41-XS offers a much larger surface area and larger pore size, as well as a shorter channel (due to the small particle size), which imply higher accessibility of the active sites. $^{21}$ It can be concluded that during the reaction in the oxidative environment the reactive intermediates tend to be overoxidized over $\mathrm{Au} / \mathrm{CuO}$ if they cannot easily access the Lewis acid sites and be converted into methyl lactate efficiently. In addition, minor amounts of other byproducts, such as dimethyl oxalate, glycerol formal, and glycerol 1,3dimethyl ether (not listed in Table S2), were obtained with the catalytic system consisting of $0.5 \mathrm{Au} / \mathrm{CuO}$ and USY, though in very minor amounts (yields less than $2 \%$ ). The latter two byproducts originated from intermolecular condensation reaction of glycerol with formaldehyde (formed by methanol oxidation) and methanol, respectively. The fact that these byproducts were only detectable with USY is probably due to the presence of strong Brønsted acid sites in this zeolite, which are known to catalyze such reactions. ${ }^{45,46}$

Moreover, $\mathrm{Au} / \mathrm{CuO}$ or Sn-MCM-41-XS was also used as the only catalyst for this reaction, which in both cases led to very low conversion of glycerol ( $<5 \%$, Table S2, entries 3 and 4 ). $\mathrm{The} \mathrm{Au} / \mathrm{CuO}$ catalyst yielded methyl glycolate as the main product ( $41 \%$ selectivity), which stems from overoxidation of glycerol. The low conversion of glycerol and the low selectivity toward methyl lactate when using $\mathrm{Au} / \mathrm{CuO}$ alone underline the importance of the presence of Sn-MCM-41-XS, not only for the overall selectivity but also to promote the conversion by catalyzing the further reaction of the intermediates obtained from the partial oxidation of glycerol. On the other hand, though the reaction showed the desired selectivity toward methyl lactate when only Sn-MCM-41-XS was used as the catalyst, the conversion of glycerol was only $2.6 \%$. These control tests confirmed that catalytic sites for promoting both the partial oxidation $(\mathrm{Au} / \mathrm{CuO})$ and the rearrangement step (Sn-MCM-41-XS) are necessary for the multistep conversion of glycerol into methyl lactate.

The multifunctional catalytic system consisting of $\mathrm{Au} / \mathrm{CuO}$ and Sn-MCM-41-XS was further studied by varying the amount of Sn-MCM-41-XS relative to the $\mathrm{Au} / \mathrm{CuO}$ catalyst (Table 4), with the purpose of optimizing the ratio between oxidative function (Au catalyst) and rearrangement function (Lewis acidity). On one hand, by increasing the amount of SnMCM-41-XS (Au/Sn molar ratio from $\sim 1 / 5$ to $\sim 1 / 20)$, the selectivity toward methyl lactate increased from $62 \%$ to $74 \%$. On the other hand, the conversion of glycerol increased from $56 \%$ to $66 \%$ by increasing the relative amount of Sn-MCM- 41 $\mathrm{XS}$ but then decreased to $54 \%$ when the $\mathrm{Au} / \mathrm{Sn}$ molar ratio was $\sim 1 / 20$. We hypothesize that the decrease in activity was due to an excessive amount of Sn-MCM-41-XS (0.4 g), which may adsorb considerable amounts of glycerol on its large surface area, thus preventing glycerol from accessing the $\mathrm{Au} / \mathrm{CuO}$ catalyst. The selectivity toward methyl lactate increased only $5 \%$ when the amount of Sn-MCM-41-XS was doubled from 0.2 to $0.4 \mathrm{~g}$. This suggests that $0.2 \mathrm{~g}$ of $\mathrm{Sn}-\mathrm{MCM}-41-\mathrm{XS}$ is a sufficient amount to promote the efficient conversion of the trioses formed by the selective oxidation of glycerol over the 
$\mathrm{Au}$ catalyst, thus granting high methyl lactate selectivity and boosting the conversion by removing the products of the oxidation.

Kinetic Experiments. The catalytic system consisting of $\mathrm{Au} / \mathrm{CuO}$ and $\mathrm{Sn}-\mathrm{MCM}-41-\mathrm{XS}$ was further investigated by performing a kinetic study until nearly full conversion of glycerol was reached (Figure 5). The conversion of glycerol is

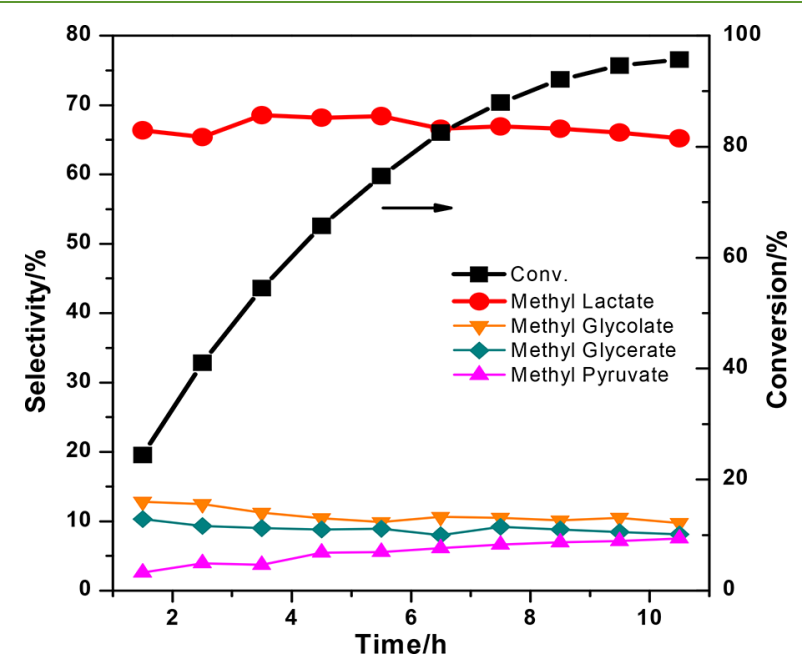

Figure 5. Kinetic test for the conversion of glycerol over the catalytic system consisting of $2 \mathrm{Au} / \mathrm{CuO}$ and $\mathrm{Sn}-\mathrm{MCM}-41-\mathrm{XS}$. Reaction conditions: temperature, $140{ }^{\circ} \mathrm{C}$; glycerol amount, $0.25 \mathrm{M}$ in 20 $\mathrm{mL}$ methanol; air pressure, 30 bar; Au catalyst, 0.05 g; Sn-MCM-41$\mathrm{XS}, 0.2 \mathrm{~g}$.

$25 \%$ after $1.5 \mathrm{~h}$ reaction and then rises almost linearly until 3.5 $\mathrm{h}$ to finally reach $96 \%$ after $10.5 \mathrm{~h}$ reaction. The TOF calculated between 1.5 and $2.5 \mathrm{~h}$ was $183 \mathrm{~h}^{-1}$. The selectivity toward methyl lactate kept steady at around $67 \%$ and only showed a minor decrease $(65 \%)$ in the last part of the reaction. This is due to a gradual increase in the selectivity toward methyl pyruvate from 3\% (at $1.5 \mathrm{~h}$ ) to $9 \%$ (at $10.5 \mathrm{~h}$ ) as a consequence of the further oxidation of the formed methyl lactate. On the other hand, the total selectivity toward the other two main byproducts, methyl glycerate and methyl glycolate, slightly decreased during the reaction, from $23 \%$ to $18 \%$, which may be caused by the further oxidation of these byproducts to $\mathrm{CO}_{2}$, as suggested by the observed decrease in carbon balance, from $>99 \%(1.5 \mathrm{~h})$ to $94 \%(10.5 \mathrm{~h})$.

Reusability. The catalytic system consisting of $\mathrm{Au} / \mathrm{CuO}$ and Sn-MCM-4-XS showed excellent reusability (Figure 6). At the optimized reaction conditions, $64 \%$ selectivity to methyl lactate at $79 \%$ glycerol conversion were obtained in the first run. The catalyst could be recycled without loss of activity (and selectivity) for five consecutive runs through straightforward washing and drying after each test. The glycerol conversion slightly dropped at the fifth run (from $79 \%$ to $72 \%)$, whereas the selectivity to methyl lactate kept constant (63\%). After regeneration by a mild thermal treatment at 200 ${ }^{\circ} \mathrm{C}$ for $3 \mathrm{~h}$ in air flow, the sixth run showed that the original glycerol conversion was restored, indicating that the small decrease in activity in the fifth run was caused by organic molecules adsorbed on catalytic surface, which could be removed by the treatment at $200{ }^{\circ} \mathrm{C}$.

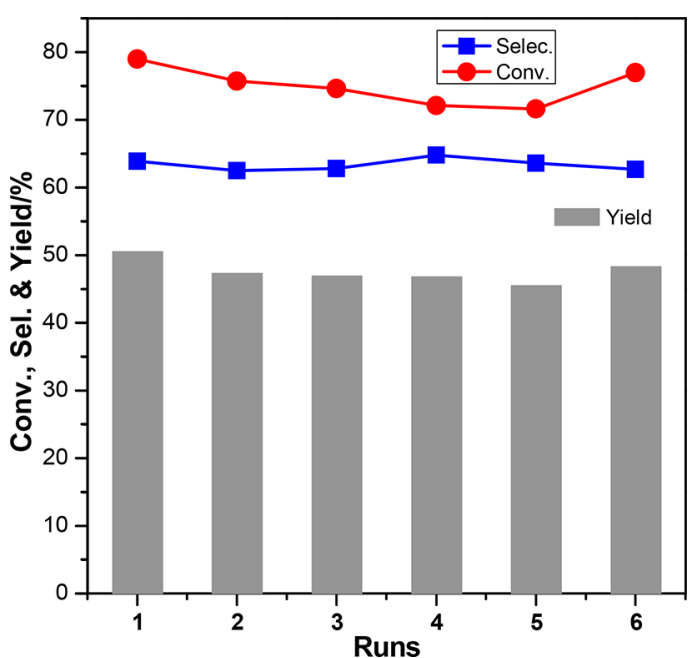

Figure 6. Reusability test of the catalytic system consisting of $0.5 \mathrm{Au} /$ $\mathrm{CuO}$ and $\mathrm{Sn}-\mathrm{MCM}-41-\mathrm{XS}$ in the conversion of glycerol to methyl lactate. Reaction conditions: temperature, $140{ }^{\circ} \mathrm{C}$; reaction time, 4.5 h; glycerol amount, $0.25 \mathrm{M}$ in $20 \mathrm{~mL}$ methanol; air pressure, $30 \mathrm{bar}$; $\mathrm{Au}$ catalyst, $0.2 \mathrm{~g}$; Sn-MCM-41-XS, $0.2 \mathrm{~g}$. The sixth run was performed after the regeneration of the catalyst by thermal treatment at $200{ }^{\circ} \mathrm{C}$ for $3 \mathrm{~h}$ in air flow.

\section{CONCLUSIONS}

Novel multifunctional catalytic systems comprising supported $\mathrm{Au}$ NPs as the oxidation catalyst and Sn-MCM-41-XS solid acid as the rearrangement catalyst were designed, synthesized, and tested for the multistep synthesis of methyl lactate from glycerol. The best catalytic system consisting of a physical mixture of $\mathrm{Au} / \mathrm{CuO}$ and $\mathrm{Sn}-\mathrm{MCM}-41-\mathrm{XS}$ achieved higher yield compared to Au/Sn-MCM-41-XS and to systems based on $\mathrm{Au}$ supported on other metal oxides. The catalyst reached $65 \%$ selectivity toward methyl lactate at $96 \%$ of glycerol conversion after $10.5 \mathrm{~h}$ of reaction. FT-IR characterization of the adsorption of $\mathrm{CO}$ and ethanol indicated that metallic $\mathrm{Au}$ NPs are the active sites for oxidation and suggested that the relatively weak interaction between reaction intermediates and $\mathrm{Au} / \mathrm{CuO}$ was beneficial for their desorption and further rearrangement over Sn-MCM-41-XS. The catalytic system based on $\mathrm{Au} / \mathrm{CuO}$ was further optimized by fine-tuning the size of the $\mathrm{Au}$ NPs supported on $\mathrm{CuO}$ by preparing the material with different $\mathrm{Au}$ loadings and different thermal treatments. The optimum balance between activity and selectivity was found for an average particle size of $3 \mathrm{~nm}$. Furthermore, the suitability of Sn-MCM-41-XS as solid acid catalyst was confirmed by its much better selectivity compared to USY in the second rearrangement step, i.e., from trioses to methyl lactate. Importantly, the Au/CuO - Sn-MCM-41-XS system exhibits excellent reusability either through a simple washing step or by mild thermal treatment at $200{ }^{\circ} \mathrm{C}$. These results are of practical importance in the context of the conversion of a biobased platform molecule as glycerol into a valuable product as methyl lactate. In a broader context, the strategy used to design this heterogeneous multifunctional catalytic system can also be beneficial for the production of other valuable chemicals from biobased resources in which multistep reactions are involved. 


\section{ASSOCIATED CONTENT}

\section{S Supporting Information}

The Supporting Information is available free of charge on the ACS Publications website at DOI: 10.1021/acssuschemeng.8b02277.

Figure $\mathrm{S} 1: \mathrm{N}_{2}$ adsorption and desorption isotherms and pore size distribution for Sn-MCM-41-XS. Figure S2: Diffuse reflectance UV-vis spectra of Sn-MCM-41-XS. Figure S3: TEM images of Au nanoparticles on various supports. Table S1: Reference catalytic tests involving the synthesis of ethyl lactate from DHA. Table S2: Reference catalytic tests involving the synthesis of methyl lactate from glycerol. (PDF)

\section{AUTHOR INFORMATION}

\section{Corresponding Author}

*E-mail: p.p.pescarmona@rug.nl.

\section{ORCID $\odot$}

Hero J. Heeres: 0000-0002-1249-543X

Paolo P. Pescarmona: 0000-0003-3608-6400

\section{Author Contributions}

The manuscript was written through contributions of all authors. All authors have given approval to the final version of the manuscript.

\section{Notes}

The authors declare no competing financial interest.

\section{ACKNOWLEDGMENTS}

We are thankful for the financial support from the China Scholarship Council for the Ph.D. grant of Zhenchen Tang, the technical support from Erwin Wilbers, Anne Appeldoorn, and Marcel de Vries, the TEM support from Dr. Marc Stuart, the UV-vis spectra support from Prof. Wesley Browne, and the ICP-OES support from Johannes van der Velde.

\section{REFERENCES}

(1) Sheldon, R. A. Green and sustainable manufacture of chemicals from biomass: state of the art. Green Chem. 2014, 16, 950-963.

(2) Serrano-Ruiz, J. C.; Luque, R.; Sepulveda-Escribano, A. Transformations of biomass-derived platform molecules: from high added-value chemicals to fuels via aqueous-phase processing. Chem. Soc. Rev. 2011, 40, 5266-5281.

(3) Zhou, C. H.; Beltramini, J. N.; Fan, Y. X.; Lu, G. Q. Chemoselective catalytic conversion of glycerol as a biorenewable source to valuable commodity chemicals. Chem. Soc. Rev. 2008, 37, $527-549$.

(4) Alonso, D. M.; Wettstein, S. G.; Dumesic, J. A. Bimetallic catalysts for upgrading of biomass to fuels and chemicals. Chem. Soc. Rev. 2012, 41, 8075-8098.

(5) Behr, A.; Eilting, J.; Irawadi, K.; Leschinski, J.; Lindner, F. Improved utilisation of renewable resources: New important derivatives of glycerol. Green Chem. 2008, 10, 13-30.

(6) Pagliaro, M.; Ciriminna, R.; Kimura, H.; Rossi, M.; Della Pina, C. From glycerol to value-added products. Angew. Chem., Int. Ed. 2007, 46, 4434-4440.

(7) Dusselier, M.; Van Wouwe, P.; Dewaele, A.; Makshina, E.; Sels, B. F. Lactic acid as a platform chemical in the biobased economy: the role of chemocatalysis. Energy Environ. Sci. 2013, 6, 1415-1442.

(8) Davis, S. E.; Ide, M. S.; Davis, R. J. Selective oxidation of alcohols and aldehydes over supported metal nanoparticles. Green Chem. 2013, $15,17-45$.
(9) Katryniok, B.; Paul, S.; Bellière-Baca, V.; Rey, P.; Dumeignil, F. Glycerol dehydration to acrolein in the context of new uses of glycerol. Green Chem. 2010, 12, 2079-2098.

(10) Wasewar, K. L.; Yawalkar, A. A.; Moulijn, J. A.; Pangarkar, V. G. Fermentation of glucose to lactic acid coupled with reactive extraction: a review. Ind. Eng. Chem. Res. 2004, 43, 5969-5982.

(11) Wang, Y.; Tashiro, Y.; Sonomoto, K. Fermentative production of lactic acid from renewable materials: Recent achievements, prospects, and limits. J. Biosci. Bioeng. 2015, 119, 10-18.

(12) Lu, T.; Fu, X.; Zhou, L.; Su, Y.; Yang, X.; Han, L.; Wang, J.; Song, C. Promotion effect of $\mathrm{Sn}$ on Au/Sn-USY catalysts for one-pot conversion of glycerol to methyl lactate. ACS Catal. 2017, 7, 72747284.

(13) Shen, Y.; Zhang, S.; Li, H.; Ren, Y.; Liu, H. Efficient synthesis of lactic acid by aerobic oxidation of glycerol on $\mathrm{Au}-\mathrm{Pt} / \mathrm{TiO}{ }_{2}$ catalysts. Chem. - Eur. J. 2010, 16, 7368-7371.

(14) Pazhavelikkakath Purushothaman, R. K.; van Haveren, J.; Melian-Cabrera, I.; van Eck, E. R.; Heeres, H. J. Base-free, one-pot chemocatalytic conversion of glycerol to methyl lactate using supported gold catalysts. ChemSusChem 2014, 7, 1140-1147.

(15) Purushothaman, R. K. P.; van Haveren, J.; van Es, D. S.; Melián-Cabrera, I.; Meeldijk, J. D.; Heeres, H. J. An efficient one pot conversion of glycerol to lactic acid using bimetallic gold-platinum catalysts on a nanocrystalline $\mathrm{CeO}_{2}$ support. Appl. Catal., B 2014, 147, 92-100.

(16) Cho, H. J.; Chang, C.-C.; Fan, W. Base free, one-pot synthesis of lactic acid from glycerol using a bifunctional Pt/Sn-MFI catalyst. Green Chem. 2014, 16, 3428-3433.

(17) Kishida, H.; Jin, F.; Zhou, Z.; Moriya, T.; Enomoto, H. Conversion of glycerin into lactic acid by alkaline hydrothermal reaction. Chem. Lett. 2005, 34, 1560-1561.

(18) Godard, N.; Vivian, A.; Fusaro, L.; Cannavicci, L.; Aprile, C.; Debecker, D. P. High-yield synthesis of ethyl lactate with mesoporous tin silicate catalysts prepared by an aerosol-assisted sol-gel process. ChemCatChem 2017, 9, 2211-2218.

(19) de Clippel, F.; Dusselier, M.; Van Rompaey, R.; Vanelderen, P.; Dijkmans, J.; Makshina, E.; Giebeler, L.; Oswald, S.; Baron, G. V.; Denayer, J. F.; Pescarmona, P. P.; Jacobs, P. A.; Sels, B. F. Fast and selective sugar conversion to alkyl lactate and lactic acid with bifunctional carbon-silica catalysts. J. Am. Chem. Soc. 2012, 134, 10089-10101.

(20) Pescarmona, P. P.; Janssen, K. P. F.; Delaet, C.; Stroobants, C.; Houthoofd, K.; Philippaerts, A.; De Jonghe, C.; Paul, J. S.; Jacobs, P. A.; Sels, B. F. Zeolite-catalysed conversion of $\mathrm{C}_{3}$ sugars to alkyl lactates. Green Chem. 2010, 12, 1083-1089.

(21) Li, L.; Collard, X.; Bertrand, A.; Sels, B. F.; Pescarmona, P. P.; Aprile, C. Extra-small porous $\mathrm{Sn}$-silicate nanoparticles as catalysts for the synthesis of lactates. J. Catal. 2014, 314, 56-65.

(22) Li, L.; Stroobants, C.; Lin, K.; Jacobs, P. A.; Sels, B. F.; Pescarmona, P. P. Selective conversion of trioses to lactates over Lewis acid heterogeneous catalysts. Green Chem. 2011, 13, 11751181.

(23) Dapsens, P. Y.; Menart, M. J.; Mondelli, C.; Perez-Ramirez, J. Production of bio-derived ethyl lactate on GaUSY zeolites prepared by post-synthetic galliation. Green Chem. 2014, 16, 589-593.

(24) Brett, G. L.; He, Q.; Hammond, C.; Miedziak, P. J.; Dimitratos, N.; Sankar, M.; Herzing, A. A.; Conte, M.; Lopez-Sanchez, J. A.; Kiely, C. J.; Knight, D. W.; Taylor, S. H.; Hutchings, G. J. Selective oxidation of glycerol by highly active bimetallic catalysts at ambient temperature under base-free conditions. Angew. Chem., Int. Ed. 2011, 50, 1013610139.

(25) Pal, P.; Sikder, J.; Roy, S.; Giorno, L. Process intensification in lactic acid production: A review of membrane based processes. Chem. Eng. Process. 2009, 48, 1549-1559.

(26) Hong, Y.-C.; Sun, K.-Q.; Han, K.-H.; Liu, G.; Xu, B.-Q. Comparison of catalytic combustion of carbon monoxide and formaldehyde over $\mathrm{Au} / \mathrm{ZrO}_{2}$ catalysts. Catal. Today 2010, 158, 415-422. 
(27) Ma, Z.; Dai, S. Development of novel supported gold catalysts: A materials perspective. Nano Res. 2011, 4, 3-32.

(28) Zhu, H.; Ma, Z.; Clark, J. C.; Pan, Z.; Overbury, S. H.; Dai, S. Low-temperature $\mathrm{CO}$ oxidation on $\mathrm{Au} /$ fumed $\mathrm{SiO}_{2}$-based catalysts prepared from $\mathrm{Au}(\mathrm{en})_{2} \mathrm{Cl}_{3}$ precursor. Appl. Catal., A 2007, 326, 8999.

(29) Wan, X.; Zhou, C.; Chen, J.; Deng, W.; Zhang, Q.; Yang, Y.; Wang, Y. Base-free aerobic oxidation of 5-hydroxymethyl-furfural to 2,5-furandicarboxylic acid in water catalyzed by functionalized carbon nanotube-supported Au-Pd alloy nanoparticles. ACS Catal. 2014, 4, $2175-2185$.

(30) Liu, S.-S.; Sun, K.-Q.; Xu, B.-Q. Specific selectivity of Aucatalyzed oxidation of glycerol and other $\mathrm{C}_{3}$-polyols in water without the presence of a base. ACS Catal. 2014, 4, 2226-2230.

(31) Villa, A.; Veith, G. M.; Prati, L. Selective oxidation of glycerol under acidic conditions using gold catalysts. Angew. Chem., Int. Ed. 2010, 49, 4499-4502.

(32) Taarning, E.; Madsen, A. T.; Marchetti, J. M.; Egeblad, K.; Christensen, C. H. Oxidation of glycerol and propanediols in methanol over heterogeneous gold catalysts. Green Chem. 2008, 10, 408-414.

(33) Corma, A.; Garcia, H. Supported gold nanoparticles as catalysts for organic reactions. Chem. Soc. Rev. 2008, 37, 2096-2126.

(34) Haruta, M. Size- and support-dependency in the catalysis of gold. Catal. Today 1997, 36, 153-166.

(35) Roy, S.; Bakhmutsky, K.; Mahmoud, E.; Lobo, R. F.; Gorte, R. J. Probing Lewis Acid Sites in Sn-Beta Zeolite. ACS Catal. 2013, 3, $573-580$.

(36) Alarcón, E. A.; Villa, A. L.; Correa, C. M. d. Characterization of Sn- and Zn-loaded MCM-41 catalysts for nopol synthesis. Microporous Mesoporous Mater. 2009, 122, 208-215.

(37) Gaydhankar, T. R.; Joshi, P. N.; Kalita, P.; Kumar, R. Optimal synthesis parameters and application of Sn-MCM-41 as an efficient heterogeneous catalyst in solvent-free Mukaiyama-type aldol condensation. J. Mol. Catal. A: Chem. 2007, 265, 306-315.

(38) Hayashi, T.; Inagaki, T.; Itayama, N.; Baba, H. Selective oxidation of alcohol over supported gold catalysts: methyl glycolate formation from ethylene glycol and methanol. Catal. Today 2006, 117, 210-213.

(39) Meyer, R.; Lemire, C.; Shaikhutdinov, S. K.; Freund, H.-J. Surface chemistry of catalysis by gold. Gold Bull. 2004, 37, 72-124.

(40) Delannoy, L.; Weiher, N.; Tsapatsaris, N.; Beesley, A. M.; Nchari, L.; Schroeder, S. L. M.; Louis, C. Reducibility of supported gold (III) precursors: influence of the metal oxide support and consequences for CO oxidation activity. Top. Catal. 2007, 44, 263273.

(41) Venkov, T.; Fajerwerg, K.; Delannoy, L.; Klimev, H.; Hadjiivanov, K.; Louis, C. Effect of the activation temperature on the state of gold supported on titania: An FT-IR spectroscopic study. Appl. Catal., A 2006, 301, 106-114.

(42) Wan, H.; Wang, Z.; Zhu, J.; Li, X.; Liu, B.; Gao, F.; Dong, L.; Chen, Y. Influence of $\mathrm{CO}$ pretreatment on the activities of $\mathrm{CuO} / \gamma$ $\mathrm{Al}_{2} \mathrm{O}_{3}$ catalysts in $\mathrm{CO}+\mathrm{O}_{2}$ reaction. Appl. Catal., B 2008, 79, 254261.

(43) Tóth, M.; Varga, E.; Oszkó, A.; Baán, K.; Kiss, J.; Erdőhelyi, A. Partial oxidation of ethanol on supported Rh catalysts: Effect of the oxide support. J. Mol. Catal. A: Chem. 2016, 411, 377-387.

(44) West, R. M.; Holm, M. S.; Saravanamurugan, S.; Xiong, J.; Beversdorf, Z.; Taarning, E.; Christensen, C. H. Zeolite H-USY for the production of lactic acid and methyl lactate from $\mathrm{C}_{3}$-sugars. $J$. Catal. 2010, 269, 122-130.

(45) da Silva, C. X. A.; Gonçalves, V. L. C.; Mota, C. J. A. Watertolerant zeolitecatalyst for the acetalisation of glycerol. Green Chem. 2009, 11, 38-41.

(46) Li, L.; Korányi, T. I.; Sels, B. F.; Pescarmona, P. P. Highlyefficient conversion of glycerol to solketal over heterogeneous Lewis acid catalysts. Green Chem. 2012, 14, 1611-1619. 